\section{VLASTOS E A NOÇÃO PLATÔNICA DE SER*}

\section{Carolina Araújo* *}

\begin{abstract}
RESUMO: Este artigo é sobre o significado de ser em Platão de acordo com Gregory Vlastos e suas consequências para a chamada teoria das ideias. Analisam-se aqui as premissas de sua interpretação do argumento do terceiro homem com o objetivo de discutir a teoria dos graus da realidade em relação ao problema da autopredicação. Neste contexto está implícita uma mudança na posição Vlastos, testemunhada sobretudo por sua posterior hipótese sobre a predicação paulina. Esta mudança revelaria - embora isso Vlastos nunca tenha aceitado - que Platão não se compromete com a autopredicação, o que exigiria uma reavaliação da teoria das ideias.
\end{abstract}

PALAVRAS-CHAVE: Platão; Vlastos; teoria das ideias; ontologia; autopredicação.

\section{VLASTOS AND THE PLATONIC NOTION OF BEING}

ABSTRACT: This paper is about the meaning of being in Plato according to Gregory Vlastos and its consequences to the so-called theory of ideas. It analyses the premises of his interpretation of the third man argument aiming to discuss the theory of degrees of reality in relation to the problem of self-predication. In this context there is a change in Vlastos' position, testified mostly by his late hypothesis about Pauline predication. This change would reveal, although Vlastos has never accepted it, that Plato is not committed to self-predication, what would require a reappraisal of the theory of ideas.

KEYWORDS: Plato; Vlastos; theory of ideas; ontology; self-predication..

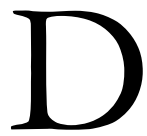

esde seu primeiro artigo de grande repercussão, The Third Man Argument in the Parmenides, de 1954, Vlastos lida continuamente, e eu diria com grande inquietação, com o sentido que os diálogos platônicos apresentam para o verbo ser e a sua consequente teoria das ideias. Meu propósito aqui é delimitar quais são, aos olhos de Vlastos, os principais problemas da noção platônica de ser e sugerir alguns pontos de investigação.
* A pesquisa, de que este trabalho é fruto, conta com o financiamento Faperj/Pronex Predicação e Existência, Capes e CNPq. ** Universidade Federal do Rio de Janeiro. 
O maior mérito do artigo de Vlastos sobre o terceiro homem foi mostrar a inconsistência entre as duas premissas implícitas no argumento que prevê o regresso infinito da grandeza no Parmênides de Platão. ${ }^{1}$ Vlastos aponta que a validade do argumento depende da verdade da prótase da sua segunda premissa, ${ }^{2}$ ou seja, a aceitação da inclusão da forma grandeza no conjunto de coisas a que é atribuído o predicado grande, leia-se a premissa da autopredicação, além da suposição, necessária para inferir a conclusão da premissa, de que o predicado não pode ser o seu próprio princípio causal, ou seja, a premissa da nãoidentidade. Identificadas as duas premissas implícitas, o argumento passa a ser não mais um regresso infinito, mas estritamente um non sequitur. ${ }^{3}$ A questão que se coloca a partir daí é: qual é a posição de Platão ao formular o argumento do terceiro homem? Diz Vlastos: "Se Platão soubesse que a sua teoria o comprometeria com essas premissas, ele não precisaria do regresso a lhe dizer que a sua teoria era logicamente moribunda e precisava de uma drástica cirurgia para sobreviver". ${ }^{4}$

Àqueles que se perguntam sobre como Vlastos entende a noção platônica de ser é importante notar dois pontos preliminares: i) Vlastos de fato considera o argumento do terceiro homem motivo para que Platão abandonasse a teoria das ideias, ao menos em

\footnotetext{
1 "Parece-me que tu consideras que cada ideia seja uma tendo como base o seguinte argumento: quando muitas coisas te parecem ser grandes, talvez te pareça que, vendo-as, haja uma certa ideia única que é a mesma sobre todas elas, donde consideras que o grande é um. Dizes a verdade, falou. Se, quanto ao grande e às outras coisas grandes, a alma os vê todos do mesmo modo, não aparecerá então uma certa unidade do grande, por meio da qual todas essas coisas aparecem como grandes? Parece que sim. Mas então surgirá uma outra ideia de grandeza, junto da qual surge o grande em si e as coisas que dele participam. E sobre todos esses, uma outra, por meio da qual tudo será grande. E assim não serão unas cada um das suas ideias, mas uma pluralidade ilimitada”. (Platão Parmênides,132a1-b2) ${ }^{2}$ Eis como Vlastos apresenta o argumento:
}

(A1) Se um número de coisas, a, b, c, são todas F, deve haver uma única ideia, F-dade, em virtude da qual nós apreendemos a, b, c, como todos $\mathrm{F}$.

(A2) Se a, b, c, e F-dade são todos F, deve haver uma outra ideia, F-dade1, em virtude da qual nós apreendemos a, b, c e F-dade como todos F.

(A3) Qualquer ideia pode ser predicada de si própria. A grandeza é ela mesma grande. F-dade é ela mesma $\mathrm{F}$.

(A4) Se qualquer coisa tem um certo caráter, ele não pode ser idêntico à ideia em virtude da qual nós apreendemos esse caráter. Se x é F, x não pode ser idêntico à F-dade.

Frente a este cenário, ele observa sobre a inconsistência entre as premissas que "(A2) inclui, ao passo que (A1) não, F-dade entre as coisas que têm a propriedade F” (Vlastos, 1954, p. 321).

${ }^{3}$ Quanto à repercussão do texto de Vlastos, ela pode ser classificada em duas grandes linhas: de um lado aqueles que defendem a autopredicação e a não-identidade das ideias platônicas, como Geach. 1956 e Bluck, 1957, por outro lado, os que não aceitam ambas as teses, como Sellars, 1955 e Allen, 1960. O interessante é notar que em todos esses casos a preocupação é de salvar a teoria da objeção exposta no argumento por um princípio de assimetria entre ideias e sensíveis no qual o problema da separação se torna central.

${ }^{4}$ Vlastos, 1954, p. 332. 
algumas de suas premissas, embora reconheça que ele não o faz mesmo depois do Parmênides; ii) Platão, para Vlastos, aponta o problema da teoria, não por detectar a inconsistência das duas premissas, mas em função do reconhecimento do regresso infinito, em um "registro de honesta perplexidade", 5 o que faria com que a teoria das ideias dos diálogos médios assumisse, como premissas tácitas, apesar de mutuamente inconsistentes, a autopredicação e a não-identidade.

O exame da suposta inconsistência da teoria platônica das ideias, tal como ela aparece nos diálogos intermediários, leva Vlastos a concluir que, na base do seu edifício ontológico, está um único sentido de ser que, ainda não purgado pela polissemia que Aristóteles lhe aplica, designa conjuntamente quatro tipos de asserção, ou seja, dizer que "x é" é dizer que: "(i) x é inteligível; (ii) x é imutável; ${ }^{7}$ (iii) x não é qualificado por predicados contrários; ${ }^{8}$ (iv) x é a instância perfeita da propriedade de relação que o termo 'x' conota". . Especificamente em relação a essa quarta qualificação, o próprio Vlastos aponta que Platão nunca a teria declarado, mas que ela, no entanto, é implicada em duas de suas teorias, a dos graus de realidade ${ }^{10}$ e a da relação de cópia com as formas, o que o compromete com a premissa da autopredicação, tendo em vista principalmente quatro passagens, Lísias 217d, Protágoras 330c-d, Fédon 100c e, indeterminadamente, o discurso de Diotima no Banquete. Antes, no entanto, de voltarmos a nossa atenção a essas passagens, gostaria de apontar, mais brevemente, o modo como a teoria dos graus de realidade aparece no artigo de 1965.

Em Degrees of Reality, Vlastos se ocupa primeiramente da ocorrência de mâllon ónta, seguida de alethéstera, na imagem da caverna. ${ }^{11}$ Não há dúvidas de que estamos, no livro VII da República, em um contexto muito mais epistêmico (ou paidêutico), do que propriamente ontológico - sendo a remissão a objetos uma premissa estabelecida anteriormente no diálogo,

\footnotetext{
${ }^{5}$ Ibid., p. 343.

${ }^{6}$ Se nos detivermos por um momento nas ocorrências citadas por Vlastos para o sentido (i) veremos que elas se aplicam mais a contextos epistêmicos do que ontológicos. Assim, nos deparamos com a linha dividida, citada como República 509d em diante, e o estabelecimento da oposição entre ser e visibilidade (boratón, noetón, 509d4), cuja única ocorrência de óntos é epistémes toû óntos te kaì noetoû theoroúmenon (511c56), o Fédon, 65c, onde a noção de ousía como ho tynkhánei hékaston ón, se opõe à aisthesis, e o Timeu, 51b-e, em que autà kath' autà ónta békasta não é perceptível pelo corpo (dià toû sómatos aisthanómetha).

${ }^{7}$ Para (ii), as referências remetem mais especificamente ao problema do realismo, com ênfase em República 484b, que afirma que os filósofos têm contato com o que sempre permanece o mesmo, ao passo que os que não são filósofos vagueiam na multiplicidade; cf. também Crátilo 439d; Fédon 78d e Filebo 59a-c.

${ }^{8}$ República 479a-c, que fala da aparência como vinculada a predicados opostos, e 523b, que fala da aparência de predicados opostos na percepção do dedo (eánte leukòs eánte mélas). Outras evidências são Fédon 74c, em que se trata de conhecer o igual em si e Carta VII 343a-b.

${ }^{9}$ Vlastos, 1954, p. 334.

${ }^{10}$ Apontando os usos de endeés e derivados como características da deficiência das coisas sensíveis em relação à noção geral de ser, em Fédon 74e, 75a-b; República 529d, em referência à distinção entre corpos celestes e ideias.

${ }^{11}$ Platão, República 515d.
} 
mais especificamente no livro V. A imagem da caverna trata de uma comparação entre estados cognitivos diversos que se projeta no comparativo entre os seus objetos ${ }^{12}$ e Vlastos aponta para isso ao dizer que "ao ver a figura do cavalo à sua frente ele 'vê mais corretamente' o que um cavalo $e$ ", ${ }^{13}$ mas a conclusão é surpreendente: “então esse 'cavalo' é 'mais real' que as suas sombras precisamente no sentido de que ele é 'mais verdadeiro' e 'mais claro'; ele permite uma melhor revelação do que um cavalo é". ${ }^{14}$ Esse princípio de que "ser" indica "o mais verdadeiro" pauta a escolha das passagens citadas e analisadas no artigo, ou seja, a seleção é feita a partir de um critério previamente estabelecido, o de que real quer dizer o que é "cognitivamente confiável, não ilusório". ${ }^{15}$

A arbitrariedade dessa seleção é então confessada pelo próprio autor, que agora, em uma afirmativa que se contrapõe explicitamente à do artigo de 1954, reconhece que este não é o único sentido de realidade para Platão, mas que, por sua conveniência e interesse naquele momento, ele o tratará como "o sentido de real para Platão". ${ }^{16}$ Quanto ao outro sentido, a este parcialmente sobreposto (overlapping), gerando uma teoria parcialmente sobreposta das ideias, Vlastos o define como o objeto de experiência mística, em que as ideias funcionam como predicados valorativos, atestando como referência República $490 \mathrm{~b}^{17}$ e $500 \mathrm{c},{ }^{18}$ além de Fedro 247c. ${ }^{19}$ Sobre a necessidade de não se confundir os dois sentidos, o argumento é que nem todas as ideias que são reais em sentido cognitivo podem sê-lo em sentido valorativo, o que República 475e atesta com a ideia do injusto e o Parmênides com a famosa objeção sobre a ideia de sujeira (130c5-d2).

Situado no meio dessa distinção de sentidos de ser, o discurso de Diotima é uma referência constante, uma vez que a ideia do belo aí referida conjuga tanto a noção de autopredicação como a de graus de realidade. Ao tratar desta última, Vlastos, no Degrees of Reality, propositadamente abandona o primeiro dos critérios diferenciais de Diotima - uma

\footnotetext{
${ }^{12}$ Mas a lista de advérbios comparativos atribuídos ao ser é aqui mais extensa: amudròn ti pròs alétheian, em República 597a; eilikrinòs óntos, em República 577a; teléos ón, em República 597a; eilikrinès e katharón em Fédon 67b; katharón, em República 585b; katharón e ámeikton, em Banquete 211e e Filebo 59c, e monoeidés em Fédon 78d e Banquete 211 b-e.

${ }^{13}$ Vlastos, 1965, p. 4.

${ }^{14}$ Ibid., p. 5.

${ }^{15}$ Ibid., p. 6.

${ }^{16}$ Ibid., p. 6.

${ }^{17} \square^{\prime \prime}$...e por meio dessa aproximação, realmente copulando com o ser, gerando o pensamento e a verdade, conhecerá, viverá e crescerá verdadeiramente e assim aplacará a dor”. (Platão, República, 490b4-7).

18 "Mas vendo e contemplando as coisas organizadas e que sempre se mantém como si mesmas, não cometendo nem sofrendo injustiças entre si, todas em ordem e mantendo a sua razão, as imita e a elas se assemelha o mais que pode". (Platão, República 500c3-6).

${ }^{19}$ Sobre Fedro 247c é de se notar que a dificuldade de Vlastos diz mais respeito ao contexto imagético da passagem como um todo do que ao vocabulário utilizado, uma vez que as formulações são condizentes com suas demais análises sobre graus de realidade. Ademais, acrescente-se a esse contexto imagético a preocupação paidêutica platônica na passagem, de que trataremos adiante.
} 
natureza que não é gerada, nem se corrompe, nem cresce, nem diminui ${ }^{20}$ - uma referência que ilustraria bem a imutabilidade do item (ii) do artigo de 54, para deter-se apenas nos critérios que, negativamente, fariam diferir os graus de realidade e, por derivação, tornariam a predicação dos sensíveis distinta da predicação das ideias. Trata-se, portanto, de exigir que o belo em si não seja: “(i) belo em um respeito e feio em outro; nem (ii) belo em um momento, mas não no outro; nem (iii) belo em relação a algumas coisas e feio em relação a outras; (iv) belo aqui, feio lá, sendo belo a alguns e feio a outros". ${ }^{21}$ Se analisamos com atenção essas condições, vemos que a ênfase na passagem do Banquete está na distinção entre a natureza do belo em si e instâncias do belo definidas sobretudo em termos de relação: perspectivas, posições relacionais e circunstâncias espaço-temporais. Se assim é, podemos assimilar a marca característica da predicação de ideias no Degrees of Reality à impossibilidade de atribuição de predicados contrários que é a nota classificatória do item (iii) do artigo de 54 sobre o terceiro homem.

O que gostaria de sugerir com este paralelo é que a teoria dos graus de realidade é fortemente limitada, no artigo posterior e na ênfase à passagem do Banquete, ao problema dos predicados contrários, o que explica a mudança de enfoque de Vlastos de uma teoria geral para uma teoria parcial do ser em Platão e essa será a estratégia do autor para rever as posições platônicas no que tange à aceitação das duas premissas implícitas do argumento do terceiro homem: a autopredicação e a não identidade. Ao concluir que as ideias são objetos perfeitamente reais que derivam como consequência da epistemologia platônica em oposição a particulares que nunca serão infalivelmente o predicado que lhes é atribuído, Vlastos está comprometendo o pensamento platônico com a premissa da não-identidade, mas isso em sentido estrito, ou seja, é preciso concluir que Platão prevê, sim, nos diálogos intermediários, que o princípio explicativo (ou mesmo ontológico) que reúne variados particulares em um mesmo predicado pode ser a causa da sua própria integração ao conjunto de entes que recebem esse predicado. Assim, em relação ao segundo de nossos pontos preliminares sobre a interpretação platônica de Vlastos, a de que Platão abandonaria a teoria das ideias no Parmênides, temos que repensá-la no sentido de que Platão formula propositadamente um argumento falacioso contra uma premissa imputada à sua teoria, mas nunca por ela sustentada: o argumento do terceiro homem, tal como Vlastos o entende, não refuta a teoria dos graus de realidade, tal como Vlastos a entende, embora ele refutasse, sim, a suposta outra concepção platônica de ser, a que envolveria a autopredicação. ${ }^{22}$

\footnotetext{
20 "Em primeiro lugar sempre é e nunca vem a ser ou perece, nem cresce ou diminui." (Platão, Banquete, 210e7-211a2).

21 "Além disso, não é belo em um aspecto e feito em outro, nem belo em um momento e não em outro, nem belo em relação a algo e feito em relação a algo outro, nem belo aqui e feio lá, como ser belo a alguns e feio a outros." (Platão, Banquete, 211a2-5).

${ }^{22}$ Como ele próprio sustentará até um de seus últimos artigos: "O que não significa que se registre aqui a rejeição da ontologia do período intermediário de Platão (...). Platão agora reconhece a gravidade das dificuldades que ele até então tinha tratado levemente, se é que tinha de fato se defrontado com elas. Ele efetua uma segunda, e muito difícil, análise da sua teoria ontológica - o que não quer dizer que ele a esteja rejeitando" (Vlastos, 1987, p. 192).
} 
Antes de tratarmos do que Vlastos chamou de noção mística do ser, gostaria de acompanhá-lo um pouco mais em seu percurso de análise das premissas implícitas do terceiro homem, que certamente não termina em 1965. O que essas análises demonstrarão é que é sobretudo um ataque à premissa da autopredicação que visa a sua hipótese das predicações paulinas, que aparece pela primeira vez no artigo de 1971, The Unity of the Virtues in the Protagoras. Se a condição para que uma sentença como "a justiça é sábia" seja verdadeira e aceita pelo Sócrates do Protágoras é a de que o predicado "ser sábio" seja atribuído, não à entidade abstrata, justiça, mas, necessariamente, a cada uma de suas instâncias, teremos aqui uma relação entre ideias e particulares um pouco distinta da anterior. Isso porque, ainda que aparentemente se trate da relação de ideias entre si, Vlastos está pensando que esta só pode se configurar a partir de uma determinada relação de cada uma das ideias com as suas respectivas instâncias. Em outras palavras, trata-se, no caso de "a justiça é sábia" de uma generalização existencial do vínculo entre justiça e sabedoria, que faz com que a noção de predicação passe a se referir à extensão (ou coextensão) da instanciação de predicados, e não a uma função identitária ou sinonímica das duas ideias entre si.

A mesma interpretação, alega Vlastos, valeria para a sentença que diz que "a justiça é justa”, que mais do que uma tautologia ou um princípio identitário, como classicamente defendeu Allen, ${ }^{23}$ deve ser lida como uma predicação paulina, indicando uma verdade analítica de que a ideia de justiça é tal que todas as suas instâncias são justas. Assim, a rigor, não se poderia mais falar em autopredicação ligada a graus de realidade. Não obstante, toda essa argumentação não basta para que Vlastos reconheça que Platão não está comprometido com a tese da autopredicação, uma vez que o artigo de 1971 vai citar os argumentos do artigo sobre o terceiro homem e retomar a ambígua posição de que, apesar de Platão nunca a ter assumido, a autopredicação é suposta em muita coisa que ele pensou e disse. Porém, pelo menos uma ressalva já é feita em 1971: agora já são entendidos como predicações paulinas os casos das passagens Lísias, 217d e Protágoras 330c-d, permanecendo como dificuldades interpretativas, Fédon, 100c e o discurso de Diotima, ou seja, dificuldades que permeiam as abordagens sobre a beleza da ideia de belo.

Até aqui temos, portanto, que reformular os dois pontos sugeridos no início do texto para indicar que, sobre (i), Vlastos deveria considerar o argumento do terceiro homem como o abandono, por parte de Platão, das suposições autopredicativas, nunca literalmente expressas, que envolveriam a teoria das ideias, ou seja, o terceiro homem se aplica à noção valorativa das ideias e à sua abordagem "mística". Já quanto a (ii), Platão não está perplexo com o terceiro homem, mas está brincando com o regresso infinito, e quiçá com a inconsistência, em que recairia uma teoria mística das ideias. Portanto Vlastos é um defensor da validade da teoria das ideias desde que ela se restrinja a um sentido mais específico de ser, em que o sentido identitário das ideias, por exemplo, da ideia de belo, seja compreendido como um sentido necessário de beleza "cognitivamente confiável, não ilusório" ou mesmo "infalível ou inalterável". ${ }^{24}$

\footnotetext{
${ }^{23}$ Allen, 1960, p. 150.

${ }^{24}$ Vlastos, 1965, p. 11.
} 
Posto isto, passo a meu último ponto, o dito sentido místico de ser. Ainda que, como sugere Vlastos, o conhecimento platônico em sentido estrito seja expresso como relações lógica e necessariamente estabelecidas entre ideias, não é meramente como infalibilidade epistêmica ou dependência cognitiva que o sentido de ser se estabelece e, sobretudo na passagem do Banquete tão cara a Vlastos, trata-se de estabelecer objetos do desejo que sejam eles mesmos independentes de circunstâncias, que possam ser necessariamente desejados e se constituírem como propósito último da educação. O que quero sustentar é que, antes de serem objetos de conhecimento, as ideias são propósito, causalidade final, ilusória e falivelmente antecipadas na busca e no processo paidêutico, identificadas à possibilidade de infalibilidade da ação. No caso do Banquete, as ideias do belo e do bom se apresentam como télos do desejo, identificado à felicidade e à total independência de fatores relativos ou transitivos de que possam decorrer resultados outros que não a felicidade. Com isso quero dizer que o sentido de falta ou menor grau dos objetos sensíveis não deve ser apenas entendido como uma distinção entre um particular espaço-temporal e um predicado sempre idêntico a si mesmo, como descreve Vlastos na última parte de Degrees of Reality, mas como a falibilidade de particulares em realizar propósitos desiderativos, uma vez que eles são localizados, transitórios, relacionais e parciais. É ter desejos que não se frustram que constitui o objetivo da paideía, resultando diretamente na felicidade da virtude, o que de certo modo dá razão a Vlastos, na sua famosa querela com Irwin, sobre o caráter instrumentalista da virtude em relação à felicidade..$^{25}$.

Não obstante, ao perseguir incessantemente argumentos que apresentem o que é o conhecimento em Platão, Vlastos se interessa muito pouco sobre como se produz esse conhecimento, o problema propriamente paidêutico. ${ }^{26}$ Notícias sobre a posição de Vlastos acerca dessa questão encontramos em seu artigo sobre o amor platônico, que, embora publicado apenas em 1973, data de 1969:

Se a ontologia de Platão tivesse sido formulada em função de propósitos estritamente semânticos e epistemológicos, ele não teria qualquer utilidade no emprego do exemplarismo e nós teríamos que ler a linguagem que o sugere como pura metáfora, libertando-a de todo o seu compromisso autopredicativo. Suponha-se que tenha sido apenas esta a intenção de Platão. Qual teria sido a consequência? Uma ontologia mais coerente, certamente - mas uma ontologia menos frutífera para os outros usos que Platão designou para as suas ideias, sobretudo para a sua teoria do amor. ${ }^{27}$

Assim compreendemos que o que Vlastos chamou de mística platônica, ou de uso valorativo das ideias, diz respeito sobretudo à função desiderativa que elas exercem sobre as almas. O que Vlastos vê como o calcanhar de Aquiles da ontologia platônica, que seria muito

\footnotetext{
${ }^{25}$ Cf. Vlastos, 1991, p. 7-9.

${ }^{26}$ É digna de nota a dedicação com que Vlastos se aplica ao problema do método socrático em contraste com o seu silêncio em relação ao método platônico.

${ }^{27}$ Vlastos, 1973a, p. 24.
} 
mais útil como tipos de realidade do que como graus de realidade, ${ }^{28}$ explica-se em função da teoria erótica. Que Vlastos nunca tenha percebido qual é o tipo de preocupação platônica ao apresentar uma especulação sobre o amor deduz-se de seu encaminhamento da questão: não por uma necessidade do pensamento platônico, mas por uma posição pessoal ou política do pensador. Ao menos é o que parece estar suposto quando ele declara que "um estudo apropriado [da teoria platônica do amor] deveria levar em consideração ao menos três coisas sobre o seu criador: ele foi um homossexual, um místico e um moralista". ${ }^{29}$ Se Vlastos não consegue superar essa estreita metodologia interpretativa, que justifica ideias pela biografia de seu autor e não por seus próprios argumentos ao defendê-las, isso certamente nos permite entender por que ele é incapaz de compreender a função da teoria erótica platônica. Nunca ocorreu a Vlastos que para Platão não fosse um princípio evidente que "todos os homens desejam por natureza conhecer". ${ }^{30}$

Vlastos nunca voltou a sugerir, como em seu primeiro artigo, que o sentido de ser em Platão fosse unívoco, ou seja, que ele tivesse uma ontologia consistente extraída de todas as suas teses sobre o ser. Apesar disso, parece-me interessante sugerir uma hipótese fundada nas premissas que ele próprio desenvolveu em seus trabalhos. No artigo sobre a unidade das virtudes, de 1971, ele reconhece como válido para Platão o seguinte princípio: "do fato de que um universal tenha certas características não se segue efetivamente que as suas instâncias tenham essas propriedades. Portanto, do fato de que a justiça seja uma entidade abstrata, invariante, incorpórea, não segue que cada um dos seres humanos que a instanciam seja uma entidade abstrata, invariante, incorpórea". ${ }^{31}$ Se é essa distinção entre propriedades de ideias e propriedades de sensíveis que serve como princípio da predicação paulina, é de se perguntar qual é a relação dos sensíveis com essas propriedades que nunca podem ser por eles instanciadas. Quando o fazemos, percebemos que a instância que apresenta as qualidades das ideias é, para Platão, o desejo em seu mais alto grau, que as apresenta como o seu objeto extremo: o que é invariante, eterno, incorpóreo, não relativo etc. O próprio Vlastos parece sugerir isso, ao dizer:

Um belo corpo, uma bela alma, uma bela criação artística, dispositivo político ou intuição científica - cada um deles satisfará por um determinado tempo e alguns deles satisfarão continuamente, mas nenhum deles satisfará completamente (...) e então esse amante platônico, cujo apetite pela beleza não é apenas voraz mas onívoro, sempre encontra um resíduo de frustração em sua presença. ${ }^{32}$

\footnotetext{
${ }^{28}$ Vlastos, 1965, p. 75.

${ }^{29}$ Vlastos, 1973 a, p. $24-25$.

${ }^{30}$ Aristóteles, Metafísica, 980a1.

${ }^{31}$ Vlastos, 1971, p. 449-450. Por sinal esta é uma tese que Vlastos sustentará até um de seus últimos artigos: "o mesmo é dizer que uma forma é em si e por si (autò kath' autó e não en autôi) e dizer que ela é separada. Que X exista separadamente de Y quer dizer que X pode existir sem que Y exista”. (Vlastos, 1987, p. 190).

${ }^{32}$ Vlastos, 1973b, p. 51.
} 
Um autor que pode reconhecer o traço de totalidade implicado no objeto platônico do desejo poderia perfeitamente se colocar a questão sobre por que as ideias são confiáveis. É o sentido valorativo das ideias, implicado na noção supostamente mística de ser, que permite reconhecer nelas os predicados que nenhum dos particulares pode apresentar, sendo, portanto, não uma noção adjacente ou parcialmente sobreposta, mas a própria possibilidade de distinção entre os dois graus de realidade.

\section{REFERÊNCIAS}

\section{Textos antigos}

ARISTÓTELES. Metafisica. Edición trilingüe por Valentín García Yebra. Madrid: Gredos, 1990.

PLATO. Phaedo. Edited by C. J. Rowe. Cambridge: Cambridge University Press, 1993.

PLATO. Protagoras. Edited by Nicholas Denyer. Cambridge: Cambridge University Press, 2008.

PLATO. Symposium. Edited by Kenneth Dover. Cambridge: Cambridge University Press, 1980.

PLATO. Platonis Rempublicam. Recognovit brevique adnotatione critica instrvxit S. R. Slings. Oxford: Clarendon, 2003.

PLATO. Opera. Tomus I. Recognovit breviqve adnotatione critica instrvxit E. A. Duke, W. F. Hicken, W. S. M. Nicoll, D. B. Robinson et J. C. G. Strachan. Oxford: Clarendon, 1995.

PLATO. Opera. Recognovit breviqve adnotatione critica instrvxit Iohannes Burnet. [5 v.] Oxford: Clarendon, 1922.

\section{Textos MODERnos}

ALLEN, R. E. Participation and Predication in Plato's Middle Dialogues. Pbilosophical Review, v. 69, p. 147-164, 1960.

BLUCK, R. S. Forms as Standards. Phronesis, v. 2, p. 115-127, 1957.

GEACH, P. T. The Third Man Again. Philosophical Review, v. 65, p. 72-82, 1956.

SELLARS, W. Vlastos and the Third Man. Philosophical Review, v. 64, p. 405-437, 1955.

STRANG, C. Plato and the Third Man. In: VLASTOS, G. Plato 1: Metaphysics and Epistemology. p. 184-200.

VLASTOS, G. The Third Man Argument in the Parmenides. Philosophical Review, v. 63, p. 319349, 1954.

VLASTOS, G. Degrees of Reality. In: BAMBROUGH, R. (Ed.). New essays in Plato and Aristotle. London: Routledge \& Kegan Paul, 1965. p. 1-19. 
VLASTOS, G. The Unity of Virtues in the Protagoras. Review of Metaphysics, v. 25, p. 415-458, 1972.

VLASTOS, G. The Individual as Object of Love in Plato. In: VLASTOS, G. Platonic Studies. Princeton: Princeton University Press, 1973a. p. 3-42.

VLASTOS, G. A Metaphysical Paradox. In: VLASTOS, G. Platonic Studies. Princeton: Princeton University Press, 1973b. p. 43-57.

VLASTOS, G. Separation in Plato. Oxford Studies in Ancient Philosophy, v. 5, p. 187-196, 1987.

VLASTOS, G. Socrates: Ironist and Moral Philosopher. Ithaca: Cornell University Press, 1991. 